\title{
ANNOUNCEMENTS \\ Training Course on Somatic Genotoxicity Assays with Drosophila: Somatic Mutation and Recombination Tests (SMART)
}

\author{
Schwerzenbach, Switzerland, September 12-23, 1988
}

The European Environmental Mutagen Society is sponsoring this course to be held at the Institute of Toxicology, Swiss Federal Institute of Technology and University of Zürich, Schwerzenbach, Switzerland, September 12-23, 1988.

The course is being organized by the Institute of Toxicology, Swiss Federal Institute of Technology and University of Zürich, Schwerzenbach, Switzerland, and Department of Radiation Genetics and Chemical Mutagenesis, University of Leiden, Leiden, The Netherlands.

The topic that will be covered is the practical performance of somatic mutation and recombination tests with Drosophila in the laboratory, including exposure of animals, registration of genotoxic effects, statistical analysis, interpretation of data, testing strategies, etc. The faculty members of the workshop will be H. Frei, U. Graf, F. E. Würgler (Schwerzenbach), and E. W. Vogel (Leiden). The language of the course will be English. For this first course the number of participants is limited to 10.

For further information and application forms please contact:

\author{
Prof. Dr. F. E. Würgler \\ Institute of Toxicology \\ Swiss Federal Institute of Technology and University of Zürich \\ Schorenstrasse 16 \\ CH-8603 Schwerzenbach, Switzerland \\ Telefax: 041-1-825-10-10
}

\section{Sixth International Neurotoxicology Conference}

\author{
Little Rock, Arkansas, October 10-14, 1988
}

The theme of the conference will be Drug Abuse and Brain Development. Internationally recognized authorities will provide a critical evaluation of clinical syndromes in which drug abuse is a major diagnostic feature. In addition, basic science researchers with an active interest in this field will be invited to discuss how their research, methodologies, and approaches are used to study drug abuse and brain development. Selected volunteer platform and poster presentations and a panel discussion will be included. Conference proceedings will be published as a Special Issue of the journal NeuroToxicology. Abstract deadline is September 1, 1988. For more information please contact:

Dr. Joan M. Cranmer
Conference Chairman
Department of Pediatrics No. 512
University of Arkansas for Medical Sciences
Little Rock, Arkansas 72205
Telephone: (501) $370-2986$ or 370-2982

367

\author{
Dr. Richard C. Wiggins \\ Program Chairman \\ Telephone: (713) 792-5735
}

Copyright $\odot 1988$ by the Society of Toxicology. All rights of reproduction in any form reserved 


\title{
Mid-America Toxicology Course
}

\author{
Kansas City, Missouri, April 17-22, 1988
}

The Mid-America Toxicology Course is a one-week intensive lecture course which will be held for the ninth time in Kansas City, Missouri, April 17-22, 1988. It will emphasize the basic science of the discipline rather than a how-to-do-it approach. It is designed to help people prepare for the American Board of Toxicology Accreditation Examination but also serves as an introduction to toxicology for interested scientists. For more information, please contact the course director:

Curtis D. Klaassen, Ph.D.

Professor of Pharmacology \& Toxicology

University of Kansas Medical Center

Kansas City, Kansas 66103

Telephone: (913) 588-7714 